\title{
Um modelo de integração de sistemas de gestão
}

\author{
Carlos Alberto de Oliveira Campos UFPE \\ Denise Dumke de Medeiros UFPE
}

\section{RESUMO}

Observa-se que há uma lacuna entre o momento da decisão de adotar um Sistema Integrado de Gestão e sua implementação. Este trabalho propõe uma abordagem sistêmica para uma etapa anterior à execução da integração, ou seja, para quando do estudo da viabilidade e elaboração de projeto. A matemática pode servir de suporte para que uma decisão não seja emocional no sentido da organização buscar seu Sistema Integrado de Gestão para estar acompanhando a tendência de seus concorrentes, mas que passe a ser racional na decisão de por que, quando, quanto, como e que sistemas integrarem. Uma vez decidindo-se pela integração de certo número de sistemas de gestão, encontrar-se-ão áreas de atividades que poderão ser enxugadas e outras que não, e estas últimas disputarão mais pelos recursos. Para reduzir o conflito e buscar a solução ótima, é proposta a aplicação de Programação Matemática.

PALAVRAS-CHAVE

Sistemas integrados de gestão, programação matemática; otimização.

\section{A model for integration of management systems}

\section{ABSTRACT}

It can be observed that there is a gap between the moment of the decision to adopt an Integrated Management System and its effective implementation. To address this problem, the present work proposes a systemic approach to the stage prior to the implementation of the integration, that is, when of the study of viability and project elaboration is being carried out. Mathematics can give support to the decision making as it is not emotional in the sense of the company using the Integrated Management Systems search just to be up-to-date with its competitors; mathematics makes the decision of why, when, how much, how and which systems to be integrated rational. When the decision to integrate certain management systems has been made, it will be clear that some activities may be pared and others not, thus reducing the competition for resources. Mathematical programming is proposed to reduce the conflict and to search for the optimum solution.

\section{KEY WORDS}

Integrated management systems, mathematical programming problem, optimization. 


\section{INTRODUÇÃO}

As organizações, para atenderem às exigências de clientes, à legislação, entre outras razões, vêm buscando a implantação do seu Sistema de Gestão da Qualidade, do seu Sistema de Gestão Ambiental e do seu Sistema de Gestão de Segurança e Saúde no Trabalho. Os Sistemas de Gestão da Qualidade (SGQ) e os Sistemas de Gestão Ambiental (SGA) normalmente abordados na literatura são aqueles baseados nas normas ISO 9001:2000 e ISO 14001:2004, respectivamente, e os Sistemas de Gestão de Saúde e Segurança no Trabalho (SGSST), baseados na norma OHSAS 18001:2007. Pombo e Magrini (2008) confirmam a tendência das empresas de integrarem seus sistemas de Gestão Ambiental, de Qualidade e de Saúde e Segurança no Trabalho. A manutenção desses sistemas separados tem gerado custos, e na busca da redução desses custos é que as organizações têm procurado implementar um sistema integrado de gestão.

Modelos de integração têm sido publicados com a finalidade de se proceder à redução de custos, pois atualmente está cada vez mais difícil e dispendioso manter dois sistemas separados, conforme Cansanção et al. (2003). Esses autores propõem um modelo de integração do SGQ e do SGA.

O escopo deste trabalho é propor um modelo de integração de sistemas de gestão dentro de uma abordagem da Teoria Geral dos Sistemas, fazendo-se uso de recursos matemáticos.

Neste texto, os sistemas de gestão a serem considerados em uma integração podem ser em um número $n$ igual ou maior do que dois, implementados totalmente ou parcialmente ou ainda não implementados, com ou sem um sistema formal documentado. A abordagem sistêmica permite que a integração seja tratada genericamente e não só como uma integração de normas de sistemas de gestão. O SIG é abordado como um supersistema (KARAPETROVIC; WILLBORN, 1998), composto por sistemas de gestão inicialmente separados. Tanto os sistemas separados, como por exemplo o SGQ com base na norma ISO 9001:2000 e o SGA com base na norma ISO 14001:2004, quanto um SIG são abordados como sistemas dinâmicos que exigem monitoramento, manutenção e flexibilidade suficiente para comportar mudanças. A programação matemática é sugerida como uma das ferramentas no monitoramento, na manutenção e na análise da viabilidade de uma integração.

Compreende-se que um sistema de gestão bem estruturado e implementado deve contemplar práticas gerenciais, instruções e manuais. As atividades, requisitos de norma, instruções, recursos humanos, procedimentos, entre outros, são denominados genericamente neste texto de itens de sistema de gestão. Cada sistema de gestão é aqui considerado isoladamente um conjunto desses itens. O Diagrama de Venn é utilizado para visualizar possíveis interseções (itens de normas em redundância) dos sistemas de gestão a serem integrados. Com o uso da análise combinatória, quantificam-se o número de interseções possíveis entre os $n$ sistemas a serem integrados. A metodologia aplicada ao trabalho foi a pesquisa exploratória, especificamente no que toca a parte da pesquisa bibliográfica realizada no início do trabalho para levantamento do estado da arte de integração de sistemas de gestão. Em seguida, foi procedida a modelagem matemática da definição do que venha a ser sistemas integrados com utilização da Teoria dos Conjuntos. Para a otimização dos

\section{$\Delta$ s organizações têm procurado implementar um SIG na busca da redução dos custos.}

recursos humanos nas atividades do sistema integrado foi aplicado o Modelo de Problemas de Transporte. Uma vez estabelecido um modelo de integração de sistemas de gestão, foi realizada uma simulação no que concerne a otimização de recursos humanos. A empresa escolhida para a simulação foi uma concessionária de energia elétrica, integrante de um dos maiores grupos do setor, que estava, no momento, realizando uma integração de seus sistemas de gestão.

\subsection{Metodologia da Pesquisa}

A metodologia aplicada é predominantemente qualitativa, que, segundo Gil (2008), quando o pesquisador procura seus dados intuitivamente, com observações sistemáticas, sua classificação em relação à abordagem é qualitativa. Quanto à natureza, a pesquisa classifica-se como aplicada, pois objetiva gerar conhecimentos para aplicação prática dirigidos à solução de problemas específicos, no caso, integração de sistemas de gestão. O presente trabalho iniciou-se com a pesquisa exploratória, especificamente, pesquisa bibliográfica. Conforme Rampazzo (2002) essa abordagem é utilizada quando se buscam maiores informações sobre determinados assuntos. Consistiu em recolher e registrar fatos do estado atual do tema Integração de Sistemas de Gestão.

A pesquisa descritiva, que segundo Rampazzo (2002) observa, registra, analisa e correlaciona fatos ou fenômenos (variáveis), foi empregada, em seguida, no estabelecimento das variáveis de estudo da modelagem matemática de sistemas integrados de gestão.

Procurando-se mostrar uma aplicação prática real do modelo apresentado, foi eleita a Companhia Energética de 
Pernambuco (CELPE), concessionária do setor de distribuição de energia elétrica, doravante denominada Empresa Estudo de Caso (EEC). Essa organização atende 2.822.982 clientes ativos (dados de abril de 2008) compreendendo consumidores de energia elétrica residencial, em sua maior parte, além de comercial e industrial. Emprega diretamente 1.752 pessoas (dados de abril de 2008). Convém ressaltar que essa organização iniciou seu processo de integração dos SGQ, SGA, SGSST e SGRS em dezembro de 2005, quando da institucionalização do comitê de integração de sistemas de gestão.

No Quadro 1 encontra-se uma sinopse da metodologia aplicada.

\section{SISTEMAS INTEGRADOS DE GESTÃO}

$\mathrm{Na}$ literatura os autores que tratam de Sistemas Integrados de Gestão (SIG) concentram-se normalmente na integração dos Sistemas de Gestão da Qualidade, dos Sistemas de Gestão Ambiental e dos Sistemas de Gestão de Saúde e Segurança no Trabalho, considerados por Wilkinson e Dale (1999) os elementos do núcleo de um SIG. De acordo com Mackau (2003), cientistas e trabalhadores práticos que têm trabalhado em questões de sistemas integrados de gestão, são mais comumente encontrados abordando os seguimentos da qualidade, proteção ambiental e saúde e segurança, os de seus maiores interesses.

Karapetrovic (2002, p. 62) exprime um sentimento de que a literatura sobre SIG ainda não é a esperada quando diz: "Apesar da literatura em SIG em jornais acadêmicos não seja de modo algum abundante.... Acredita-se que seja devido ao tema integração de sistemas de gestão ser relativamente recente.

Conforme Wilkinson e Dale (1999) boa parte da literatura sobre SIG, os estudos de casos, tem tratado algumas vezes a integração mais como uma discussão secundária do que como principal foco de atenção. Por outro lado, o setor químico tem demonstrado particular interesse em integração de sistemas de gestão (SISSELL, 1996). Esses mesmos autores consideram que há um crescente interesse na integração de sistemas de gestão.

Desde o artigo de Wilkinson e Dale (1999) até a presente data, têm surgido na literatura artigos, dissertações de mestrado e teses de doutorado abordando o assunto integração de sistemas de gestão. A própria norma de Sistemas de Gestão da Qualidade ISO 9001:2000 contempla a possibilidade de integração de sistemas de gestão: "esta norma possibilita a uma organização o alinhamento ou a integração de seu sistema de gestão da qualidade com outros requisitos de sistemas de gestão relacionados". A norma refere-se aos Sistemas de Gestão Ambiental, Gestão de Segurança e Saúde Ocupacional, Gestão Financeira ou de Risco.

Sobre o que vem a ser Sistema Integrado de Gestão, não há ainda um consenso na definição. Willborn e Dale (1999) afirmam que há diferenças na interpretação do que integração signifique e como ela deva ser efetuada e que isso leva a uma necessidade urgente de definições. Esses mesmos autores apresentam uma proposta, talvez não completa, mas bastante esclarecedora sobre integração de sistemas: "interconectando dois sistemas de forma que isso resulte na perda de independência de um ou dos dois, significa que esses sistemas estão integrados", sem que os sistemas individualmente percam suas identidades. É questionado se essa perda implica necessariamente em redução de flexibilidade. Crowe (1992) aponta que em sistemas de produção, a integração tem freqüentemente levado a redução de flexibilidade. Além disso, indaga-se sobre até que ponto compensa o ganho da integração em detrimento, se for o caso, de redução de flexibilidade. Acredita-se que a resposta deve ser procurada caso a caso num estudo de balanceamento de perdas e ganhos em que certamente uma programação matemática caberá perfeitamente como ferramenta para a tomada de decisão.

Wilkinson e Dale (1999, p. 98) esclarecem que "colocar sistemas separados em um único manual de políticas e procedimentos não é integrá-los". Continuando, eles afirmam que, "Para a integração, todas as práticas gerenciais devem

\section{Quadro1: Sinopse da Metodologia Aplicada.}

\begin{tabular}{ccc}
\hline Etapas & Classificação & Aplicação \\
\hline 1 & Pesquisa Exploratória. & $\begin{array}{c}\text { Pesquisa bibliográfica para estudos e registros do estado atual } \\
\text { do tema Integração de Sistemas de Gestão. }\end{array}$ \\
2 & Pesquisa Descritiva & $\begin{array}{r}\text { Estabelecimento de variáveis empregadas na modelagem } \\
\text { matemática do modelo proposto. }\end{array}$ \\
3 & Estudo de Caso & Estudo da viabilidade do modelo proposto em caso real. \\
\hline
\end{tabular}

Fonte: os autores (2008) 
ser colocadas em um único sistema, mas não como componentes separados". Enfim, para a integração, as normas, suas similaridades e diferenças devem ser identificadas, práticas gerenciais devem estar em um só sistema tendo as instruções e manuais dos sistemas individuais completamente fundidos.

O reconhecimento nacional e internacional de normas, como a da qualidade ISO 9001, não se constitui condição sine qua non para uma integração. Uma organização que tenha seu próprio sistema de gestão, bem estruturado e documentado (norma de gestão interna), como por exemplo de gestão de manutenção, poderá fazer uso do mesmo para integração com outros sistemas. Boa parte dos autores da literatura pesquisada analisa a integração dos sistemas de gestão com base em normas internacionais. $\mathrm{O}$ fato de não haver um documento formal de uma estrutura de gestão não significa que não exista um ou mais sistemas coexistindo dentro de uma organização. Evidente que havendo uma norma, interna ou externa, bem disseminada dentro de uma organização já é um bom começo, mas não é suficiente, pois outras dificuldades podem surgir. Cansanção et al. (2001) observam que em todos os modelos de SIG apresentados, uma das principais dificuldades de implantação é a mudança de cultura. Convém acrescentar outros pontos que podem dificultar a integração, sem querer esgotar o assunto, como recursos humanos, financeiros e materiais, como fatores importantes a serem considerados.

A seguir são apresentados dois dos modelos encontrados na literatura, para integração de sistemas de gestão.

\subsection{Modelo de Karapetrovic e Willborn}

Esses autores exemplificam seu modelo trabalhando a integração do SGQ e do SGA com base na ISO 9001 e na ISO 14001. Karapetrovic e Willborn (1998) tratam a integração de sistemas de gestão separadamente da integração de sistemas de auditorias, provavelmente por considerarem as normas de auditoria de sistemas da qualidade e ambiental razoavelmente bem avançadas no que concerne o aspecto integração, como citam. De fato, em sendo a integração total ou parcial, em nada contraria tratar os sistemas de auditorias separadamente dos sistemas de gestão. Esse tratamento pode ser entendido como uma integração parcial, tornando-se total quando os sistemas integrados de auditorias forem, por sua vez, integrados aos sistemas de gestão, já integrados.

Os autores apresentam três estratégias para a implantação de um sistema integrado:

- Implementar primeiro o SGQ e depois o SGA;
- Implementar primeiro o SGA e depois o SGQ;

- Implementar o SGQ e o SGA simultaneamente.

A primeira estratégia beneficia aquelas organizações que já possuem seu SGQ implantado. Por exemplo, os registros ambientais, segundo os autores, podem ser identificados, documentados e controlados utilizando-se os procedimentos já existentes do controle de registros da qualidade fundindo-se em um só controle de registros. As auditorias do SGA podem ser estabelecidas com base nas auditorias internas da qualidade.

\section{No que contrarie alguns autores, as normas de gestão, por mais importantes que sejam, são apenas alguns dos elementos de integração.}

A segunda estratégia, para Karapetrovic e Willborn (1998), é vantajosa para as organizações que não possuem ainda seus SGQ e SGA implantados, mas que estejam sob elevada pressão pública para um estabelecimento urgente de um SGA.

Karapetrovic e Willborn (1998) advogam a terceira estratégia e apresentam as seguintes vantagens:

- Estabelecimento de um sistema de gerenciamento integrado e de desempenho otimizado desde o início;

- Participação mais detalhada de todas as partes interessadas;

- Uso reduzido de recursos múltiplos;

- Uso de efeito sinergia no desenvolvimento de ambos os sistemas;

- Harmonização na resolução de problemas comuns no início do projeto;

- Otimização de custos;

- Flexibilidade e possibilidades aumentadas para incluir outros sistemas.

A proposta dos dois autores é que a gerência deve pensar e agir globalmente para começar a implantação dos sistemas, começando com as características e exigências comuns dos SGQ e do SGA. Os requisitos comuns da ISO 9001 e ISO 14001 são também apresentados por Karapetrovic e Willborn (1998).

O modelo de Karapetrovic e Willborn (1998) para o desenvolvimento de um sistema integrado objetiva a melhoria de desempenho. Para a integração, os itens das normas dos sistemas de gestão a serem integrados são agrupados em seis grupos:

- Saída desejada;

- Projeto do sistema; 
- Alocação;

- Distribuição;

- Implementação dos sistemas;

- Saída atual.

\subsection{Modelo de Integração de Cansanção}

O objetivo da integração, segundo Cansanção et al. (2003), é minimizar e otimizar o sistema de gerenciamento. Esse mesmo autor apresenta uma proposta de modelo de integração dos sistemas de gestão com base nas normas ISO 9001 e ISO 14001, dividido em três etapas, a saber:

- Modelo sistêmico do SIG, composto pelos elementos fornecedores, organização e clientes, que interagem constantemente;

- Descrição do modelo utilizando ISO 9001 e ISO 14001 cujos requisitos de normas são integrados e distribuídos entre os níveis estratégico, tático e operacional, com o objetivo de minimizar e otimizar o sistema de gerenciamento;

- Metodologias de implantação do modelo, que é baseada nas seguintes etapas de implementação: diagnóstico inicial do sistema de gerenciamento da organização; identificação dos sistemas de gerenciamento da organização; classificação dos sistemas de gerenciamento da qualidade da organização; classificação dos sistemas de gerenciamento ambiental da organização; classificação de outros sistemas de gerenciamento da organização; avaliação do nível de maturidade dos sistemas. da aplicação de seu modelo para a integração do SGQ e do SGA são:

- Descrição em nível sistêmico, baseado nas normas ISO 9001 e ISO 14001, detalhamento das estratégias de integração;

- Modelo flexível, podendo se ajustar à realidade das organizações;

- Baseado em normas de reconhecimento internacional;

- Sistema enxuto de documentação e melhora na performance operacional;

- Redução e programação de múltiplas auditorias;

- Possibilita melhoria da competitividade e redução de custos da organização;

- Possui foco na satisfação e manutenção do cliente;

- Maior contato com clientes e fornecedores e imagem positiva na sociedade;

- As desvantagens do modelo apresentado, segundo Cansanção et al. (2003), são:

- Necessidade de mudança na cultura da organização;

- Aumento dos custos na fase de implantação do SIG;

- O modelo é teórico e ainda não foi aplicado.

\subsection{Comentários sobre a Bibliografia}

Karapetrovic e Willborn (1998) aplicam em seu modelo as normas ISO 9001 e ISO 14001 agrupando os assuntos nos seis grupos já citados. Isso permite melhor identificação dos itens em comum das normas. O modelo é de simples compreensão e aplicação. Dentre as vantagens da integração enunciada por aqueles autores, podemse destacar a otimização de recursos e o uso reduzido de recursos múltiplos.

Em seu trabalho, Cansanção et al. (2003) abordam dois sistemas de gestão, o da Qualidade e o Ambiental, e apre-

Ainda, dentro da metodologia de implantação do SGI do citado autor, as três estratégias de Karapetrovic e Willborn (1998) são utilizadas:

- Utilizar a estrutura do SGQ existente como suporte para implementação e integração do SGA;

- Utilizar a estrutura do SGA existente como suporte para implementação e integração do SGQ;

- Quando não houver nenhum dos sistemas SGQ e SGA ainda implementado, implementá-los e ao mesmo tempo integrá-los.

Cansanção et al. (2003) consideram que o nível de maturidade do sistema de gerenciamento junto com as três estratégias baliza o grau de dificuldade de implantação de um sistema integrado.

As vantagens apresentadas por Cansanção et al. (2003) sentam também modelos de SIG de quatro indústrias. Esses autores apresentam as vantagens da integração e partem para a apresentação do seu modelo de integração.

Não há um consenso sobre a ordem de integração dos sistemas, por exemplo, Karapetrovic e Willborn (1998) dão preferência a integração simultânea do SGQ, do SGA e do SGSST, alegando como uma das várias vantagens a redução do uso de recursos múltiplos. Já Correia (2002) considera a dificuldade de integração menor se já houver um sistema implantado com base na ISO 9001.

Dentro da bibliografia levantada sobre SIG, os sistemas de gestão abordados pelos autores compreendem os Sistemas de Gestão da Qualidade, Ambiental, Saúde e Segurança no Trabalho (SGSST), sendo as normas respectivamente, ISO 9001, 14001 e OHSAS 18001. Outros sistemas de gestão para serem integrados com esses como, por exemplo, os Sistemas 
de Gestão de Suprimento e o de Gestão de Manutenção, não foram identificados. Via de regra, os modelos de integração identificados na pesquisa bibliográfica limitam-se aos SGQ, SGA e SGSST, aqueles considerados por Wilkinson e Dale (1999) os elementos do núcleo de um SIG.

Também não foi observado um modelo para o monitoramento dos sistemas integrados, uma vez que sendo o SIG dinâmico há que se pensar em um sistema de manutenção. Observa-se ainda, dentro da literatura pesquisada, que não foi dada uma ênfase na fase anterior ao trabalho de integração, ou seja, de um estudo da viabilidade de uma integração para um dado momento da organização. A programação matemática pode servir de apoio à tomada de decisão de, o que e quando integrar, além disso, servir de ferramenta para um monitoramento do desempenho do sistema integrado. $\mathrm{O}$ resultado do monitoramento permitirá a tomada de decisão sobre o SIG, se o mesmo deve ser mantido, desfeito totalmente ou parcialmente, como também se é conveniente acrescentar outros sistemas.

$\mathrm{Na}$ literatura pesquisada, os autores não abordam a possibilidade de um sistema integrado de gestão poder vir a apresentar não-conformidades, ou seja, falhas, durante as suas atividades (quando em operação). Os autores pesquisados partem de suas vantagens e desvantagens para uma integração, porém sem haver uma aplicação matemática sobre o assunto integração.

Este trabalho propõe uma visão sistêmica mais generalizada de integração de sistemas quaisquer de gestão e não necessariamente os SGQ, SGA e SGSST. Muito embora não haja consenso na literatura sobre o que venha a ser integração de sistemas de gestão, o objetivo deste trabalho é propor que a integração de sistemas de gestão não se limite ao alinhamento de normas de gestão como pretendem os diversos autores da bibliografia apresentada, e tampouco a apenas três ou quatro sistemas de gestão.

Através da Teoria dos Conjuntos, é apresentada, como alternativa, a definição de SIG. Sob a abordagem da Teoria Geral dos Sistemas, consideram-se três conjuntos fundamentais para a integração de sistemas de gestão, o conjunto das Atividades, o conjunto dos Elementos e o conjunto das Relações entre esses elementos, mas isso não tem sido abordado na literatura sobre SIG. No que contrarie alguns autores, as normas de gestão, por mais importantes que sejam, são apenas alguns dos elementos de integração, e os sistemas de auditorias, ferramentas imprescindíveis de avaliação de sistemas, ou seja, elementos de SIG. O Sistema Integrado de Gestão, neste trabalho, é visto não como um fim em si, mas como meio de se atingir objetivos organizacionais. Isto quer dizer que não se parte para a realização de um SIG sem que esteja evidenciado que através dele alcançar-se-ão as metas da organização. A Programação Matemática pode ser aplicada nos estudos de integração de sistemas de gestão. Neste trabalho, é apresentada uma aplicação na fase de estudos da integração dos elementos dos sistemas, quando esses forem os recursos humanos.

\section{MODELO DE INTEGRAÇÃO DE SISTEMAS DE GESTÃO}

Utilizar a Teoria dos Conjuntos para entender melhor o assunto SIG parece ser bem apropriado, considerando que a Teoria Geral dos Sistemas supõe, entre outros, a Teoria dos Conjuntos, como afirma Maciel (1974).

Uma integração de sistemas de gestão pode ser vista como a união de todos os sistemas, produzindo um sistema mais complexo Z, que pode ser visualizado na Equação 1 a seguir.

$$
Z=S_{1} \cup S_{2} \cup \ldots \cup S_{n}
$$

onde $Z$ é o próprio Sistema Integrado de Gestão e $S_{1}, S_{2}, \ldots S_{n}$ são os sistemas de gestão a serem integrados. Dessa forma, compreende-se que não há limite para o número $n$ de sistemas de gestão a serem integrados e que a definição $Z$ de um SIG passa a ser mais abrangente do que o encontrado na literatura.

Todo sistema é composto de elementos ou partes que interagem entre si através de suas entradas e saídas (abordagem de processo), com vistas a um objetivo comum. Conforme Maciel (1974), um sistema se define através de três conjuntos disjuntos, que são o conjunto dos Elementos (E), o conjunto das atividades (A) e o conjunto das Interações (I). Dessa forma, cada sistema de gestão Si é da forma apresentada na Equação 2 a seguir.

$$
S_{i}=\{E, A, I\}
$$

Identificar as interseções dos sistemas de gestão a serem integrados, na forma da Equação 2, possibilita a redução de redundâncias, ou seja, redução de custos operacionais. $\mathrm{O}$ número $\mathrm{N}$ de possíveis condições, interseções e não interseções, entre $n$ sistemas de gestão, pode ser encontrado na Equação 3. 
$N=1+C_{n}^{2}+C_{n}^{3}+C_{n}^{4}+\ldots+C_{n}^{n} \quad n$ inteiro e $n \geq 2$

onde $C_{n}^{2}, C_{n}^{3}{ }_{n},{ }_{n}^{4}$ e $C_{n}^{n}$ são as combinações de $n$ sistemas de gestão tomados dois a dois, $n$ sistemas de gestão tomados três a três, $n$ sistemas de gestão tomados quatro a quatro e $n$ sistemas de gestão tomados $n$ a $n$, respectivamente.

Ilustra-se na Figura 1 um Diagrama de Venn com três dos sistemas de gestão, de um conjunto universo $U$ de todos os sistemas de gestão.

Compreende-se, a partir da Equação 2, que parte da redução de custos com uma integração de $n$ sistemas de gestão consistirá de reduções de interseções dos $n$ sistemas e da identificação dos elementos dessas interseções. Outro aspecto é que o conjunto $Z$ da Equação 1 representa a integração de sistemas de gestão independentemente de haver ou não interseção. Isso quer dizer que, no limite, mesmo não se encontrando nenhuma correspondência entre as normas dos sistemas de gestão a serem integrados, mesmo não havendo atividades e interações redundantes, pode-se ter integração. Isso vai de encontro às colocações de que integração de sistemas de gestão seja alinhamento de normas e um enxugamento de atividades redundantes. Mesmo não havendo interseções uma integração poderá ser viável se o SIG for mais eficiente que os sistemas isolados ou trouxer vantagens competitivas e estratégicas.

A integração de sistemas de gestão produz um supersistema, dentro da terminologia de Maciel (1974) e, portanto, um sistema $\mathrm{Z}$ bem mais complexo que suas partes $\mathrm{S}_{\mathrm{i}}$ isoladamente. Dessa forma, uma integração de sistemas de gestão pode ser realizada parcialmente, sem envolver todos os elementos, mas quer seja parcial ou total há que se considerar um estudo para a sua realização. Para a elaboração de um SIG, este trabalho propõe três fases:

FASE 1

- Objetivos para a integração dos sistemas de gestão;

- Análise do estado atual dos sistemas $s$ serem integrados. Identificar:

- Objetivos dos sistemas de gestão a serem integrados

- O Conjunto Elementos

- O Conjunto Atividades, com suas entradas, saídas, tempo de produção, processadores e ambientes e ruídos.

- O Conjunto Interações

- O Fluxo de informação

- Os Indicadores de desempenho adotados

- Síntese do estado atual. Utilizar a abordagem de processo;

- Custo de cada sistema isolado.

FASE 2

- Projeto de Integração;

- Alocação de Recursos Financeiros.

FASE 3

- Treinamento;

- Implementação;

- Monitoramento;

- Manutenção;

- Melhoria contínua.

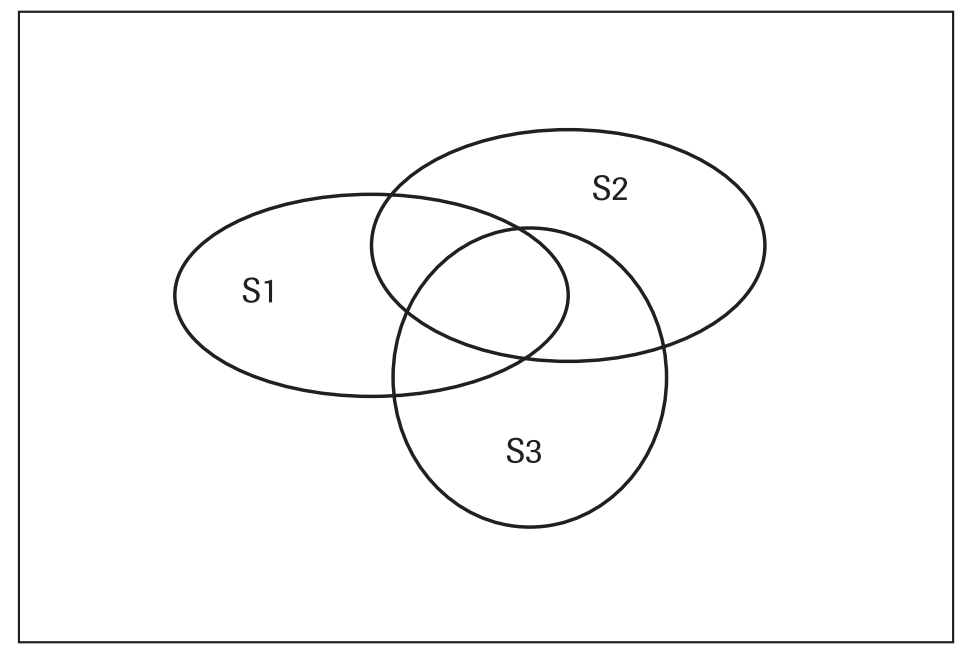

Figura 1: 0 Diagrama de Venn de sistemas de gestão

Fonte: os autores (2008) 
Pode-se considerar a Fase 1 como a fase preparatória para a integração, onde se inicia pela necessidade estratégica da empresa em realizar a integração de seus sistemas de gestão. Conhecer o estado atual e procurar eliminar suas falhas para não correr o risco de se formar um supersistema (SIG) com as deficiências anteriores. Conhecer os custos dos sistemas antes da integração permite utilizá-los como parâmetro comparativo com os custos do SIG formado. Enfim, os dados obtidos nesta fase servirão de base para a Fase 2, seguinte. O projeto na Fase 2 deve compreender não só o alinhamento de normas, mas levar em consideração a integração de recursos humanos, de recursos materiais, financeiros e assim por diante. O SIG em abordagem de processo, na forma da Figura 4, com as suas atividades e tempos de execução e acoplamentos com outras atividades, permite uma visão sistêmica geral do SIG e constitui-se uma excelente ferramenta de análise. De posse do projeto de integração e dos recursos para a sua implementação passa-se para a Fase 3 que é concretizar o SIG. É de se esperar reações às mudanças necessárias para a realização da integração dos sistemas de gestão. O treinamento não só tem por objetivo a preparação para a execução das atividades do SIG, mas produzir estímulos no sentido de se reduzir ou eliminar as esperadas resistências às mudanças. Uma vez o SIG implementado faz-se necessário monitorá-lo e realizar os ajustes que se fizerem necessários para se atingir os objetivos previstos na Fase 1. A manutenção do SIG compreende também a dos recursos humanos, materiais e financeiros, sem os quais o sistema integrado tenderá a degenerar-se.

Entende-se que sem a anuência da alta gerência a dificuldade de se implementar qualquer sistema de gestão ou mantê-lo fica bastante ampliada. Quando da execução do projeto deve-se considerar isso, sendo as interações, neste trabalho, classificadas como:

Nula: quando não há qualquer tipo de interação mesmo quando deveria haver;

Fraca: ocorre informalmente, espontaneamente ou voluntariamente. Em outras palavras, ela não é institucional e poderá ser interrompida por quaisquer dos lados com ou sem conhecimento da organização;

Forte: quando é institucionalizada, embora necessária ou não. O seu rompimento só deve ocorrer com a anuência da organização.

A integração dos recursos humanos tem sido pouco considerada na literatura, mas ela é, se não a mais importante, pelo menos uma das partes mais importantes para o sucesso do SIG. O recurso humano está presente nas três fases do estudo de integração de sistemas de gestão. Na Fase 1, quan- do do levantamento do estado atual dos sistemas a serem integrados, na Fase 2, quando do projeto que define quem, quanto, e o que fazer, e na Fase 3, quando do treinamento e execução das atividades. Para a Fase 2, no auxílio da definição de para definição de quem, quanto e o que fazer, no sentido de se atingir o ótimo com o menor custo possível, foi desenvolvida a Equação 4, a partir do Modelo de Transportes, da Programação Matemática. Para melhor compreensão do desenvolvimento dessa equação, apresenta-se o exemplo a seguir.

\section{EXEMPLO DE APLICAÇÃO DE PROGRAMAÇÃO MATEMÁTICA}

Uma organização deseja integrar dois sistemas de gestão $S_{1}$ e $S_{2}$ já em operação. Sejam $a_{1}$ e $a_{2}$ as quantidades máximas de tarefas produzidas nos sistemas $S_{1}$ e $S_{2}$, respectivamente, quando integrados. Pretende-se trabalhar com três empregados, $E_{1} E_{2}$ e $E_{3}$ no sistema integrado. Os empregados são considerados aptos para desenvolverem o conjunto de tarefas $a_{1}$ e $a_{2}$ dos sistemas $S_{1}$ e $S_{2}$, mas possuem salários diferenciados e produtividades diferentes. Seja $c_{i j}$ o custo unitário do empregado $E_{j}$ para realizar uma tarefa a $i$ do sistema $S_{i}$ e, $b_{j}$ a capacidade média do empregado de realização dessa tarefa. Pretende-se distribuir as tarefas $\mathrm{a}_{i}$ entre os empregados $E_{j}$ de forma a minimizar o custo total na realização das tarefas do sistema integrado.

Seja $x_{i j}$ a quantidade de tarefa $a_{i}$ que o empregado $E_{j}$ deve realizar de forma a minimizar os custos com o sistema integrado.

A modelagem matemática para o problema é dada pela Equação 4, a seguir, onde o valor de $\mathrm{F}$ representa o custo total com a integração dos recursos humanos que se deseja minimizar.

$$
\begin{gathered}
F=c_{11}+x_{11}+c_{12}+x_{12}+c_{13}+x_{13}+c_{21} \\
+x_{21}+c_{22}+x_{22}+c_{23}+x_{23}
\end{gathered}
$$

O custo unitário $c_{\mathrm{i}}$ pode ser obtido, por exemplo, com os valores homem-hora dos empregados e do tempo padrão (TP). É desejável que a capacidade de realização de tarefas dos empregados, dada por $\sum_{j=1}^{3} b j$, absorva a quantidade de 

tarefas do sistema integrado dada por $\sum_{i=1}^{2} a_{i}$. A Equação 5
mostra essa relação.

$$
\sum_{1=1}^{2} a_{i}=\sum_{j=1}^{3} b_{j}
$$

A quantidade de tarefa $\mathrm{a}_{1}$ é distribuída nas quantidades $\mathrm{x}_{11}$ para o empregado $\mathrm{E}_{1}, \mathrm{x}_{12}$ para o empregado $\mathrm{E}_{2}$ e $\mathrm{x}_{13}$ para o empregado $E_{3}$ de forma que:

$$
\mathrm{a}_{1}=x_{11}+x_{12}+x_{13} \therefore a_{1}=\sum_{j-1}^{3} x_{1 j}
$$

Por extensão, $a_{2}=x_{21}+x_{22}+x_{23}=\sum_{j-1}^{3} x_{2 j}$

A quantidade total de tarefas do sistema integrado é dada por: $a_{1}+a_{2}=\sum_{1=1}^{2} a_{i}$

A Equação 4 está sujeita às seguintes restrições:

- Quanto à quantidade de tarefas dos sistemas de gestão:

$$
x_{11}+x_{12}+x_{13}=a_{1}
$$

ou seja, a quantidade de tarefas $a_{1}$ é distribuída para os empregados $\mathrm{E}_{1}, \mathrm{E}_{2}$ e $\mathrm{E}_{3}$ nas quantidades $\mathrm{x}_{11}, \mathrm{x}_{12}$ e $\mathrm{x}_{13}$ respectivamente.

Continuando nesta linha de raciocínio,

$$
x_{21}+x_{22}+x_{23}=a_{2}
$$

- Quanto à absorção de tarefas por parte dos empregados:

$$
x_{11}+x_{21}=b_{1}
$$

ou seja, o empregado $E_{1}$ pode absorver as tarefas $\mathrm{x}_{11}$ e $\mathrm{x}_{21}$

Por extensão:

$$
\begin{aligned}
& x_{12}+x_{22}=b_{2} \\
& x_{13}+x_{23}=b_{3}
\end{aligned}
$$

- Condição de positividade das variáveis:

$$
x_{11}, x_{12}, x_{13}, x_{21}, x_{22}, x_{23} \geq 0
$$

A modelagem matemática de distribuição de tarefas em um sistema integrado com $m$ sistemas de gestão e $n$ empregados pode ser generalizada como mostra a Equação 6.

$$
\text { Minimizar } F=\sum_{i=1}^{m} \sum_{j=1}^{n} c_{i j} x_{i j}
$$

sujeito à: $\sum_{j=1}^{n} x_{i j}=a_{i} \quad$ quantidade de tarefas

positividade das variáveis $x_{i j}$

$\sum_{i=1}^{m} x_{i j}=b_{j}$ absorção de tarefas por parte do Empregado $\mathrm{E}_{\mathrm{i}}$ $x_{i j} \geq 0 \quad i=1,2,3, \ldots, m$ e $j=1,2,3, \ldots, n \quad$ na condição de positividade das variáveis.

Devido às limitações de espaço editorial, o trabalho restringe-se à Fase 1. Este exemplo, longe de querer ser completo, objetiva evidenciar aspectos ainda não abordados na literatura sobre integração de sistemas de gestão, bem como esclarecer a aplicação do modelo proposto. Assim, escolheuse o estudo de integração do Sistema de Gestão da Qualidade, representado pelo Controle da Qualidade de Material (CQM), com o Sistema de Gestão Ambiental (SGA), ambos já em funcionamento na organização. O objetivo do SIG, segundo a organização, é aumentar a eficiência dos sistemas de gestão mantendo ou reduzindo-se os custos.

As atividades foram levantadas através de entrevista com os gestores das áreas e com as pessoas diretamente responsáveis pela execução das atividades, ou seja, os elementos ativos do conjunto Elementos. Procurou-se dar uma abordagem de processo às atividades buscando-se identificar as entradas, processadores e respectivas saídas, sendo consideradas as atividades os processadores (os elementos ativos da atividade os próprios executores das atividades juntamente com seus recursos de apoio). As atividades identificadas foram agrupadas de $A_{1}$ a $A_{7}$ para o CQM e de $\mathrm{A}_{8}$ a $\mathrm{A}_{12}$, para o SGA. Dentro de cada atividade há as partes técnicas e suas respectivas partes administrativas inerentes ao processo. Muito embora essas partes administrativas já estejam integradas às atividades de $A_{1}$ a $A_{12}$, buscou-se evidenciá-las como $a_{1}, a_{2}, \ldots, a_{7}$, com a intenção de se verificar, antes da integração dos sistemas de gestão, se não se teria um custo menor compartilhando-se as atividades administrativas entre os sistemas, uma vez que, na EEC o homem-hora administrativo é normalmente menor que o técnico. O CQM da EEC abrange as seguintes atividades com suas respectivas entradas e saídas:

- $\mathrm{A}_{1}=$ Inspeção de Materiais. A inspeção de recebimento dos materiais, adquiridos ou vindos do fabricante pelo Exercício da Garantia, é realizada nos laboratórios dos Fabricantes (Fab), no laboratório da EEC ou no Almoxarifado (Almx). A entrada é o pedido de inspeção (do fabricante ou almoxarifado) e a saída é o resultado da inspeção contida no documento Boletim de Inspeção de Material (BIM) para o Fabricante e para o Almoxarifado. $\mathrm{Na}$ Figura 2, é apresentada uma abordagem de processo para esta atividade, mas foram omitidas entradas e saídas do Almoxarifado e de Compras que não dizem respeito à atividade $\mathrm{A}_{1}$.

- $\mathrm{A}_{2}=$ Ensaios. Ensaios elétricos e mecânicos são realizados no laboratório CQM. Os ensaios atendem às necessidades da inspeção, da triagem, do Exercício da Garantia, da análise de protótipo, da análise de desempenho de material. 
Atende também às necessidades das diversas unidades da EEC e de outras organizações externas à EEC. A entrada é o pedido de ensaios dos Diversos (Div) interessados e a saída é o resultado dos ensaios contido no documento Certificado de Ensaio para os solicitantes (Div). Na Figura 3 , mostra-se uma abordagem de processo para esta atividade, mas foram omitidas entradas e saídas dos Diversos (Div) solicitantes que não dizem respeito à atividade $\mathrm{A}_{2}$.

- $\mathrm{A}_{3}=$ Avaliação Industrial. A Auditoria de Sistemas da Qualidade é aplicada aos fabricantes que têm seu SGQ implementado com base nos requisitos da ISO 9001. A finalidade da avaliação é a seleção de fabricantes para compor o cadastro da unidade de Compras da EEC. A entrada é o pedido de avaliação industrial por parte da unidade de Compras e a saída é o resultado da avaliação contido no Relatório de Avaliação Industrial, para Compras. Foram omitidas entradas e saídas da unidade de Compras, que não dizem respeito à atividade $\mathrm{A}_{3}$.

OBS.: a abordagem de processo deve ser realizada para cada atividade com o objetivo de facilitar a execução da abordagem de processo para todo o sistema. Aqui será omitida para o restante do processo.

- $\mathrm{A}_{4}=$ Análise de Protótipo. A entrada é a solicitação de análise de protótipo por parte das diversas unidades da EEC e a saída é o resultado da análise contido no documento Resultado de Análise de Protótipo. A saída alimenta as especificações de compra de material, de responsabilidade da unidade de Engenharia Básica e o cadastro de fornecedores da unidade de Compras. Foram omitidas entradas e saídas de Compras e de Engenharia Básica, que não dizem respeito à atividade $\mathrm{A}_{4}$.

- $\mathrm{A}_{5}=$ Análise Técnica de Licitação. A entrada é a solicitação

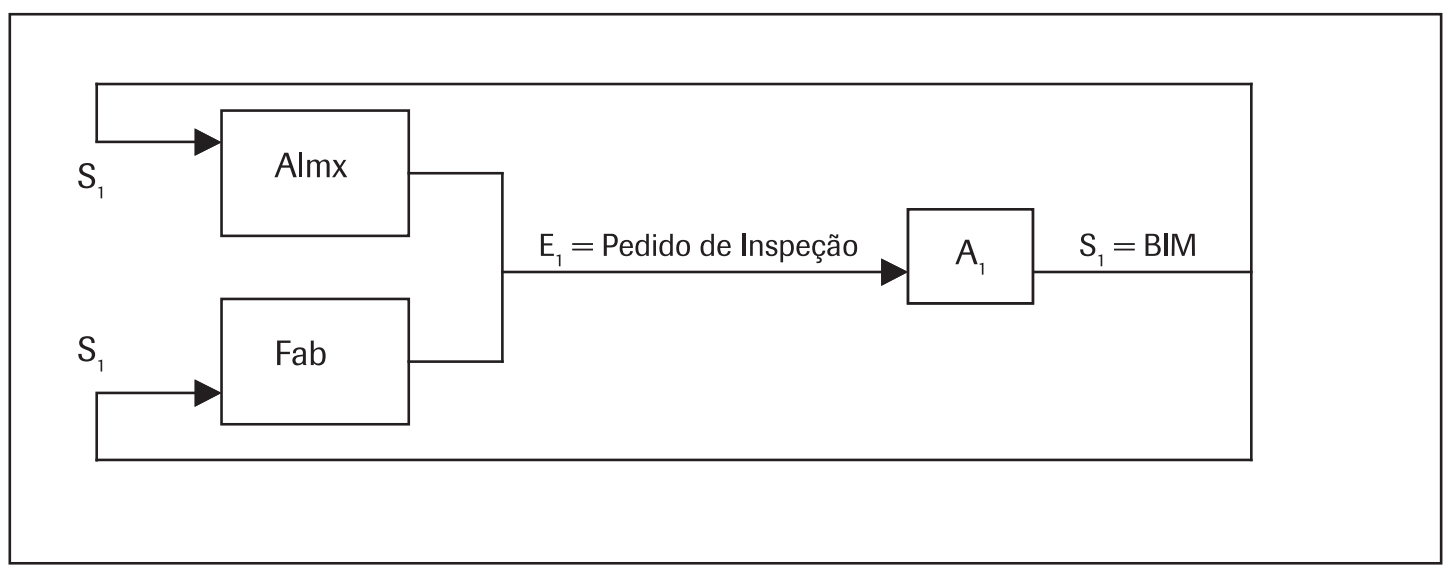

Figura 2: Abordagem de Processo para a atividade $A_{1}$

Fonte: os autores (2008)

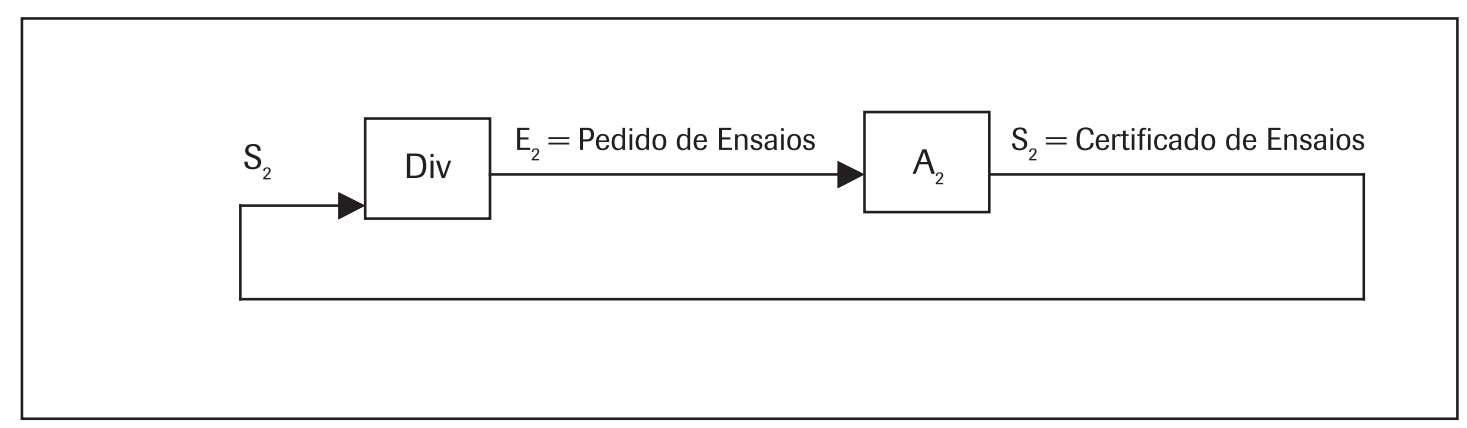

Figura 3: Abordagem de Processo para a atividade $A_{2}$

Fonte: os autores (2008) 
de análise técnica de licitação pela unidade de Compras e a saída é o Resultado da Análise contido no documento Processo de Licitação. Foram omitidas entradas e saídas de Compras, que não dizem respeito à atividade $A_{5}$.

- $\mathrm{A}_{6}=$ Avaliação de Desempenho de Material. A entrada é o pedido de avaliação de material por parte das diversas unidades (Div.) ou por parte do Almoxarifado e a saída é o resultado da avaliação contido no documento Avaliação de Material que alimenta as especificações de compra de material (de responsabilidade da unidade de Engenharia Básica), o Exercício da Garantia $\left(\mathrm{A}_{7}\right)$ e o cadastro de fornecedores de Compras. Foram omitidas entradas e saídas de Compras, de Engenharia Básica (Eng. Básica), das diversas unidades (Div.), Almoxarifado e da atividade $\mathrm{A}_{7}$, que não dizem respeito à atividade $\mathrm{A}_{6}$.

- $\mathrm{A}_{7}=$ Exercício da Garantia. A entrada é o resultado da atividade Análise de Desempenho de Material $\left(\mathrm{A}_{6}\right)$ dentro da garantia e a saída é confirmação ao Fabricante e Almoxarifado de falha no material dentro do prazo de garantia. Foram omitidas entradas e saídas da atividade A6, do Almoxarifado (Almx) e do Fabricante (Fab) que não dizem respeito à atividade $\mathrm{A}_{7}$.

As atividades seguintes são desmembramentos de algumas das atividades anteriores, portanto já foram apresentadas as suas abordagens de processo.

- $a_{1}=$ Controle de Boletins de Inspeção de Material (BIM). Atividade administrativa de $\mathrm{A}_{1}$ que compreende o controle, emissão de números de BIM, preenchimento dos dados preliminares, recebimento, baixa e catalogação.

- $\mathrm{a}_{2}=$ Liberação de Embarque de Material. Atividade administrativa da atividade A1 que consta da liberação de embarque de materiais que não serão inspecionados em fábricas e, sim, no laboratório da EEC ou no seu almoxarifado.

- $\mathrm{a}_{3}=$ Elaboração de Relatórios de Atividades: Atividade administrativa com os dados de produção de cada mês das atividades do CQM.

Existem outras atividades administrativas como atendimento telefônico, atendimento aos representantes, clientes, entre outras, que não foram apresentadas por limitação editorial.

Convém esclarecer que a palavra material está sendo utilizada no seu sentido mais amplo, significando também equipamento, instrumento e fardamento.

\subsection{Medida dos Tempos de Atividades (Processamentos)}

Uma etapa importante na integração de sistemas de gestão é o levantamento dos tempos de execução das atividades, no entanto é de difícil realização, uma vez que as variáveis são inúmeras. Por exemplo, na atividade $\mathrm{A}_{1}$ (inspeção de materiais), com centenas de variedades de itens de compra e a quantidade a ser adquirida, pode ser considerada uma variável aleatória. A metodologia adotada foi a de se medir o tempo de execução de $n$ tarefas idênticas e depois dividir esse tempo por $n$, considerando-se assim como uma média, o tempo de execução da atividade. O tempo foi obtido dentro da rotina normal de trabalho, começando no momento em que o executor recebe a incumbência da tarefa até a sua conclusão, incluindo-se interrupções tais como atendimento de ligação telefônica, pausa para um cafezinho, etc. Enfim, não se procurou medir o tempo de execução estrita da tarefa, mas o tempo real de processamento.

Há que se distinguir do intervalo de tempo entre os momentos da entrada no processo e o momento da saída, o tempo despendido exclusivamente para a tarefa. Por exemplo, embora o resultado da análise de protótipo dure um ano, o tempo dedicado pelo executor da tarefa é bem menor do que isso. Um tratamento estatístico poderia ser dado, verificando-se o nível de confiança desejado, a quantidade de observações necessárias e quando as observações deveriam ser realizadas, no entanto foge do escopo do que se pretende com este exemplo de aplicação do modelo proposto.

No caso específico da atividade de inspeção esta poderia ser desmembrada em famílias de material e por grupos de tamanho de lote, mas para o que se propõe o exemplo, o tempo médio foi obtido de todos os materiais e tamanhos de lote.

Nas Tabelas 1, 2 e 3 encontram-se os resultados do levantamento da situação Atividades sob abordagem de processo: os processadores (atividades), as entradas e suas respectivas fontes, os tempos médios de processamento, as saídas e seus respectivos destinatários.

Fica então determinado o conjunto A das Atividades da Inspeção, como sendo:

$$
A=\left\{A_{1}, A_{2}, \ldots, A_{7}\right\}
$$

\subsection{Identificação dos Elementos do Conjunto Interações}

Outro conjunto constituinte de um sistema é o das interações, que, após levantamento na área do CQM, foi identificado como a seguir.

\section{Interação com Compras ( $\left.\mathrm{I}_{1}\right)$}

A interação é forte sendo as atividade do CQM organizacionalmente subordinadas a Compras. Compras recebe o pedido de material dos diversos usuários da EEC. Caso não tenha em estoque, abre um processo de aquisição que por sua vez contém um processo de licitação entre os fabricantes 
cadastrados. O CQM é responsável pela avaliação do Sistema da Qualidade (SQ) do fabricante e pela avaliação do material. Caso seja um material nunca utilizado pela EEC, então o CQM, conjuntamente com a Engenharia Básica e o órgão usuário farão a avaliação do material. Compras recebe todas as propostas dos fabricantes contendo as partes comercial e técnica. A análise técnica das propostas dos fabricantes é realizada pelo CQM. Os resultados da avaliação do SQ do fabricante e os resultados das inspeções dos materiais alimentam o cadastro dos fornecedores (fabricantes) da unidade Compras.

\section{Interação com Engenharia Básica $\left(\mathrm{I}_{2}\right)$}

A interação da Inspeção com a Engenharia Básica é fraca. A Engenharia Básica convida o CQM para participar da análise de um material ainda não utilizado na EEC ou para comentar sobre uma dada especificação de material em elaboração ou revisão. Por sua vez, o CQM, quando da aplicação das especificações na atividade de inspeção de materiais, poderá dar retorno à Engenharia Básica, mas sem nenhuma obrigação institucional. Considerando que a atividade de inspeção faz uso das especificações de compras elaboradas pela Engenharia Básica e que essas podem ser atualizadas e aprimoradas com o feedback da inspeção, sugere-se que esta interação deveria ser fortalecida (institucionalizada).

\section{Interação com o Fabricante $\left(\mathrm{I}_{3}\right)$}

A interação com o Fabricante é dita forte porque ela é institucionalizada. Ela se dá no processo de Avaliação

Tabela 1: Dados sobre os processadores para abordagem de processo do SGQ.

\begin{tabular}{|c|c|c|c|}
\hline $\begin{array}{c}\text { Processadores } \\
\text { (Atividades) }\end{array}$ & Entrada $(E)$ & $\begin{array}{l}\text { Tempo médio de } \\
\text { Processamento }\end{array}$ & Saída (S) \\
\hline$A_{1}=$ Inspeção de Material & $\begin{array}{l}\mathrm{E}_{1}=\text { solicitação de inspeção do } \\
\text { fabricante ou do almoxarifado }\end{array}$ & $8 \mathrm{~h} /$ lote & $\begin{array}{l}\mathrm{S}_{1}=\text { BIM para Compras e } \\
\text { Almoxarifado }\end{array}$ \\
\hline$A_{2}=$ Ensaios & $\begin{array}{l}\mathrm{E}_{2}=\text { solicitação de ensaios de diversas } \\
\text { partes (Div) }\end{array}$ & $4 \mathrm{~h} /$ unid & $\begin{array}{l}\mathrm{S}_{2}=\text { Certificado de Ensaios para as } \\
\text { diversas partes (Div) }\end{array}$ \\
\hline$A_{3}=$ Avaliação Industrial & $\begin{array}{l}\mathrm{E}_{3}=\text { solicitação de avaliação de } \\
\text { Compras }\end{array}$ & 24 h / fábrica & $\begin{array}{l}\mathrm{S}_{3}=\text { Relatório de Avaliação para } \\
\text { Compras }\end{array}$ \\
\hline$A_{4}=$ Análise de Protótipo & $\begin{array}{l}\mathrm{E}_{4}=\text { solicitação de análise de protótipo } \\
\text { de diversas unidades (Div) }\end{array}$ & Não determinado & $\begin{array}{l}\mathrm{S}_{4}=\text { Resultado da análise de protótipo } \\
\text { para as diversas unidades (Div) }\end{array}$ \\
\hline $\begin{array}{l}\mathrm{A}_{5}=\text { Análise Técnica de } \\
\text { Licitação }\end{array}$ & $\begin{array}{l}\mathrm{E}_{5}=\text { solicitação de análise técnica de } \\
\text { licitação de Compras }\end{array}$ & $24 \mathrm{~h} /$ processo & $\begin{array}{l}\mathrm{S}_{5}=\text { Resultado da Análise Técnica de } \\
\text { Licitação para Compras }\end{array}$ \\
\hline $\begin{array}{l}A_{6}=\text { Avaliação de } \\
\text { Desempenho de Material }\end{array}$ & $\begin{array}{l}\mathrm{E}_{6}=\text { solicitação de avaliação de } \\
\text { desempenho de diversas unidades (Div) }\end{array}$ & Não determinado & $\begin{array}{l}\mathrm{S}_{6}=\text { Resultado da Avaliação para } \\
\text { Compras e Engenharia Básica }\end{array}$ \\
\hline $\begin{array}{l}\mathrm{A}_{7}=\text { Exercício da } \\
\text { Garantia }\end{array}$ & $\begin{array}{l}\mathrm{E}_{7}=\text { solicitação do exercício da garantia } \\
\text { de diversas unidades (Div) e do } \\
\text { Almoxarifado (Almx) }\end{array}$ & Não determinado & $\begin{array}{l}\mathrm{S}_{7}=\text { BIM para Compras e o } \\
\text { Almoxarifado }\end{array}$ \\
\hline
\end{tabular}

Fonte: os autores (2008)

Tabela 2: Dados sobre a administração para abordagem de processo do SGQ.

\begin{tabular}{llll}
\hline \multicolumn{1}{c}{$\begin{array}{c}\text { Parte administrativa dos } \\
\text { processos }\end{array}$} & \multicolumn{1}{c}{ Entrada $(\mathrm{E})$} & \multicolumn{1}{c}{ Saída (S) } & \multicolumn{1}{c}{ Produção anual } \\
\hline $\mathrm{a}_{1}=$ Controle de BIM & $\begin{array}{l}\mathrm{E}_{10}=\text { solicitação de inspeção do } \\
\text { fabricante ou do almoxarifado }\end{array}$ & $\begin{array}{l}\mathrm{S}_{10}=\text { Emissão de BIM para o } \\
\text { inspetor e BIM arquivado }\end{array}$ & 2.841 \\
$\begin{array}{l}\mathrm{a}_{2}=\text { Liberação de Embarque de } \\
\text { Material }\end{array}$ & $\begin{array}{l}\mathrm{E}_{15}=\text { solicitação de inspeção do } \\
\text { fabricante }\end{array}$ & $\begin{array}{l}\mathrm{S}_{15}=\text { Material liberado para } \\
\text { fabricante embarcar }\end{array}$ & Sem registro \\
$\begin{array}{l}\mathrm{a}_{3}=\text { Elaboração de Relatórios } \\
\text { de Atividades }\end{array}$ & $\mathrm{E}_{14}=$ solicitação de compras & $\mathrm{S}_{14}=$ Relatório para Compras & 12 \\
\hline
\end{tabular}

Fonte: os autores (2008) 
Industrial, na Análise de Protótipo, na Análise Técnica de Licitação, na Inspeção e no Exercício da Garantia.

\section{Interação com a Manutenção $\left(\mathrm{I}_{4}\right)$}

A interação com a Manutenção é fraca. Ocorre informalmente quando da avaria de materiais dentro ou fora do prazo de garantia, quando da avaliação conjunta com a Engenharia Básica de novos materiais e quando de consultas técnicas diversas por parte da Manutenção. Considerando que a interação com a Manutenção poderá trazer importantes subsídios às atividades de inspeção e elaboração de especificações, sugerese o fortalecimento (institucionalização) dessa interação.

\section{Interação com os $\mathrm{ER}\left(\mathrm{I}_{5}\right)$}

A interação com os Escritórios Regionais (ER) é fraca. Ocorre quando do mau funcionamento de algum material, dentro ou fora do prazo de garantia, quando da instalação de um novo protótipo no sistema elétrico ou quando da avaliação de algum material doado ou retirado do estoque.

\section{Interação com a Logística ( $\left.\mathrm{I}_{6}\right)$}

A interação com a Logística é fraca. Ela ocorre pressionando a inspeção para liberar o mais rapidamente possível o material comprado ou inversamente, para atrasar a entrada de material no estoque. Considerando que a atividade de inspeção não deve sofrer pressões no sentido de aceitação de material sem passar por todo o processo, sugere-se a anulação dessa interação.

\section{Interação com Segurança no Trabalho $\left(I_{7}\right)$}

A interação é fraca. Ocorre na análise de protótipo de
Equipamentos de Proteção Individual (EPI) e de Equipamentos de Proteção Coletiva (EPC). Sendo a aquisição e aprovação de EPI e EPC de responsabilidade exclusiva da Segurança no Trabalho e sendo o CQM especialista em materiais sua interação forte é recomenda.

\section{Interação com Clientes para Ensaios $\left(\mathrm{I}_{8}\right)$}

A interação com os Clientes para a venda de ensaios no laboratório do CQM é fraca, sendo mais uma iniciativa pessoal da coordenação da CQM e a inércia do status quo de Clientes que tradicionalmente vêm solicitando ensaios ao laboratório do CQM. Como essa interação não diz respeito ao SGQ da EEC, sendo mais novo negócio a ser explorado ou não, deve a organização decidir pela anular ou fortalecer essa interação.

\section{Interação com Qualidade do Produto $\left(\mathrm{I}_{9}\right)$}

A interação com a qualidade do produto é nula, e isso é um elo fraco na corrente da qualidade.

$\mathrm{Na}$ Tabela 4 apresentam-se as interações com suas respectivas classificações institucionais, suas vantagens e as classificações desejáveis.

O conjunto I das interações ficou determinado como sendo:

$$
\mathrm{I}=\left\{\mathrm{I}_{1}, \mathrm{I}_{2}, \ldots, \mathrm{I}_{8}\right\}
$$

A parte do Sistema de Gestão da Qualidade, Controle da Qualidade de Materiais, é então dada por:

$$
\mathrm{CQM}=\{\mathrm{E}, \mathrm{A}, \mathrm{I}\}
$$

\begin{tabular}{|c|c|c|}
\hline Processadores (Atividades) & Saída (S) & Produção anual \\
\hline$A_{1}=$ Inspeção de Material & $\mathrm{S}_{1}=\mathrm{BIM}$ para Compras e Almoxarifado & 2.841 \\
\hline$A_{2}=$ Ensaios & $\mathrm{S}_{2}=$ Certificado de Ensaios, para as diversas partes & 86 \\
\hline $\mathrm{A}_{3}=$ Avaliação Industrial & $\mathrm{S}_{3}=$ Relatório de Avaliação, para Compras & 6 \\
\hline$A_{4}=$ Análise de Protótipo & $\begin{array}{l}\mathrm{S}_{4}=\text { Resultado da análise de protótipo para as diversas } \\
\text { unidades }\end{array}$ & 6 \\
\hline$A_{5}=$ Análise Técnica de Licitação & $\begin{array}{l}\mathrm{S}_{5}=\text { Resultado da Análise Técnica de Licitação para } \\
\text { Compras }\end{array}$ & 30 \\
\hline$A_{6}=$ Avaliação de Desempenho de Material & $\begin{array}{l}\mathrm{S}_{6}=\text { Resultado da Avaliação para Compras e Engenharia } \\
\text { Básica }\end{array}$ & Sem registro \\
\hline$A_{7}=$ Exercício da Garantia & $\begin{array}{l}\mathrm{S}_{7}=\text { Material recuperado ou reposto para Compras e o } \\
\text { Almoxarifado }\end{array}$ & Sem registro \\
\hline
\end{tabular}

Tabela 3: Dados sobre as atividades da inspeção para abordagem de processo do SGQ. 
(o conjunto E, foi omitido por razões de espaço editorial)

Na Figura 4 é apresentada a síntese do SGQ, representado pelo CQM, em abordagem de processo. Esta síntese constitui-se em uma das mais fortes ferramentas para um estudo de integração de sistemas de gestão, pois permite visualizar as interações dos elementos do sistema.

\subsection{Sistema de Gestão Ambiental (SGA)}

O Sistema de Gestão Ambiental adotado na EEC tem como base os requisitos da norma de gestão ISO 14001 . Encontra-se implantado e certificado em poucas áreas da organização. O estudo do processo de implantação para to- das as unidades restantes ainda está em processo de estudos junto à comissão de integração.

O mesmo procedimento realizado com o SGQ foi para o SGA, mas que por motivos de limitação editorial é apresentado resumidamente nas Tabelas 5 e 6 .

\subsection{Integração dos Sistemas de Gestão}

De posse das sínteses do SGQ e do SGA em abordagem de processo pode-se mais facilmente fazer estudos e analisar a integração dos dois sistemas, analogamente como se faria para dois circuitos elétricos.

A Equação 3, para o caso dos dois sistemas fica sendo

Tabela 4: Classificação das Interações dos elementos do CQM.

\begin{tabular}{|c|c|c|c|}
\hline Interações & $\begin{array}{l}\text { Classificação } \\
\text { atual }\end{array}$ & $\begin{array}{l}\text { Classificação } \\
\text { desejável }\end{array}$ & Justificativa \\
\hline $\mathrm{I}_{1}$ & Forte & Forte & A interação vem funcionando satisfatoriamente \\
\hline $\mathrm{I}_{2}$ & Fraca & Forte & Agrega valor na elaboração das especificações e realimenta-as \\
\hline $\mathrm{I}_{3}$ & Forte & Forte & A interação vem funcionando satisfatoriamente \\
\hline $\mathrm{I}_{4}$ & Fraca & Forte & $\begin{array}{l}\text { A Inspeção tem bastante penetração junto ao fabricante, } \\
\text { o que facilita o exercício da garantia. }\end{array}$ \\
\hline$I_{5}$ & Fraca & Forte & Obtêm-se respostas do desempenho dos materiais. \\
\hline $\mathrm{I}_{6}$ & Fraca & Nula & $\begin{array}{l}\text { A Logística pode monitorar melhor seu cronograma de entregas } \\
\text { conhecendo a real situação das inspeções. }\end{array}$ \\
\hline $\mathrm{I}_{7}$ & Fraca & Forte & Obtêm-se respostas do desempenho dos materiais. \\
\hline$I_{8}$ & Fraca & Nula ou Forte & $\begin{array}{l}\text { Nula porque sai do foco das atividades da Inspeção. Poderá ser forte se houver } \\
\text { interesse econômico nos ensaios ou interesse de se criar um diferencial no } \\
\text { atendimento aos grandes clientes da EEC, que é o caso de algumas Empresas. }\end{array}$ \\
\hline $\mathrm{I}_{9}$ & Nula & Forte & $\begin{array}{l}\text { Sem a retroalimentação da qualidade do produto, o CQM } \\
\text { fica sem poder fazer os necessários ajustes. }\end{array}$ \\
\hline
\end{tabular}

Fonte: os autores (2008)

Tabela 5: Dados sobre os processadores para abordagem de processo do SGA.

\begin{tabular}{cccc}
\hline Processadores (Atividades) & Saída (S) & Tempo de produção & Produção anual \\
\hline $\begin{array}{c}\mathrm{A}_{8}=\text { Licenciamento dos } \\
\text { empreendimentos }\end{array}$ & $\mathrm{S}_{1}=$ licença regularizada & 160 h/empreend. & 90 \\
$\mathrm{~A}_{9}=$ Suporte técnico & $\mathrm{S}_{2}=$ solicitações atendidas & $112 \mathrm{~h} /$ consulta & 180 \\
$\mathrm{~A}_{10}=$ Elaboração de & $\mathrm{S}_{3}=$ documentos elaborados & 16 h/documento & 15 \\
documentos normativos & $\mathrm{S}_{4}=$ treinamento realizado & 2 h/treinamento & 70 \\
$\mathrm{~A}_{11}=$ Treinamentos diversos & $\mathrm{S}_{5}=$ auditoria realizada & 48 h/auditoria & 4 \\
\hline
\end{tabular}


$\mathrm{N}=1+C_{2}^{2}=2$, ou seja, só há duas condições a serem examinadas, ou não existe interseção ou há interseção a ser examinada entre os dois sistemas. Para o caso de apenas dois sistemas, isso é óbvio, mas quando o número de sistemas a serem integrados aumenta, a Equação 3 é bastante útil.

O SGQ é administrado por quatro empregados $\mathrm{E}_{1}, \mathrm{E}_{2}, \mathrm{E}_{3}$ e $\mathrm{E}_{4}$ e o $\mathrm{SGA}$ por, $\mathrm{E}_{5}, \mathrm{E}_{6}$ e $\mathrm{E}_{7}$, que com no máximo 8 horas de treinamento estariam aptos a atender todas am atividades administrativas de ambos os sistemas.

Os custos unitários das tarefas $\mathrm{a}_{\mathrm{i}}$ serem realizadas pelo empregado $E_{j}$, dados por $c_{i j}$, não foram fornecidos, assim como as capacidades $\mathrm{b}_{j}$ máximas de cada empregado realizar as tarefas $\mathrm{a}_{i}$. A quantidade da atividade $i$ que deve ser designada ao empregado $j$, de forma a minimizar os custos com a integração das atividades administrativas é dado por $\mathrm{x}_{\mathrm{ij}}$.

A equação da integração dos recursos humanos para as atividades administrativas do SIG, a partir da Equação 6, é dada por:

$$
\operatorname{Min} F=\sum_{i=1}^{m} \sum_{j=1}^{n} c_{i j} x_{i j}
$$

sujeito à:

- Quantidade de tarefas:

$x_{11}+x_{12}+\ldots+x_{17}=2.841$

$x_{71}+x_{72}+\ldots+x_{77}=70$

- Produtividade Média dos Empregados:

$x_{11}+x_{21}+\ldots+x_{71}=b_{1}$

$x_{17}+x_{27}+\ldots+x_{77}=b_{7}$

- Condição de positividade das variáveis

$x_{i j} \geq 0 \quad i=1,2,3, \ldots, m$ e $j=1,2,3, \ldots, n$

Conforme o objetivo, da integração, os custos dos SIG devem ser menores ou iguais. Além disto, foi considerado

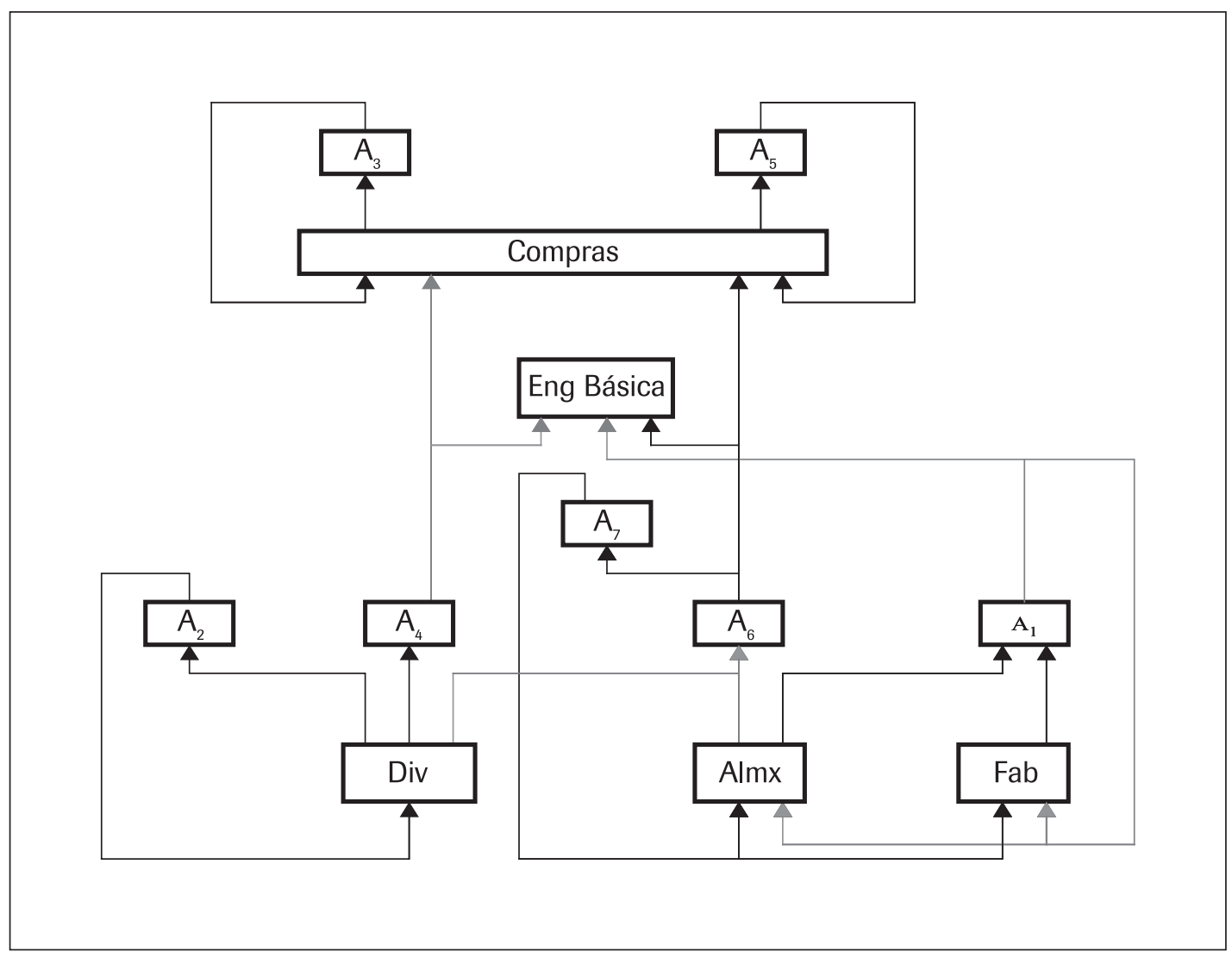

Figura 4: Síntese do Sistema de Controle da Qualidade de Material em abordagem de processo. 
Tabela 6: Dados sobre a administração para abordagem de processo do SGA.

\begin{tabular}{lccc}
\hline Processadores (Atividades) & Saída $(\mathrm{S}$ ) & Tempo de produção & Produção anual \\
\hline $\begin{array}{c}\mathrm{a}_{4}=\text { parte administrativa } \\
\text { do Licenciamento dos } \\
\text { empreendimentos }\end{array}$ & $\mathrm{S}_{1}=$ licença regularizada & $\mathrm{t}_{4} \mathrm{~h} /$ empreend. & 90 licenciamentos \\
$\mathrm{a}_{5}=\begin{array}{c}\text { parte administrativa do } \\
\text { Suporte técnico }\end{array}$ & $\mathrm{S}_{2}=$ solicitações atendidas & 180 suportes técnicos \\
$\begin{array}{c}\mathrm{a}_{6}=\text { parte administrativa da } \\
\text { Elaboração de documentos } \\
\text { normativos }\end{array}$ & $\mathrm{S}_{3}=$ documentos elaborados & $\mathrm{t}_{5} \mathrm{~h} /$ consulta & 15 documentos elaborados \\
$\begin{array}{c}\mathrm{a}_{7}=\text { parte administrativa dos } \\
\text { Treinamentos diversos }\end{array}$ & $\mathrm{S}_{4}$ h/documento treinamento realizado & $\mathrm{t}_{7} \mathrm{~h} /$ treinamento & 70 treinamentos \\
\hline
\end{tabular}

Fonte: os autores (2008)

que cada empregado executa com a mesma produtividade as $\mathrm{a}_{m}$ atividades administrativas dos SGQ e do SGA, que a produtividade de cada empregado pode ser diferente um do outro, que o homem-hora de cada empregado difere um do outro.

\section{CONSIDERAÇÕES FINAIS}

Não há consenso sobre o que venha a ser integração de sistemas de gestão e sobre como realizar a integração e, via de regra, a literatura tem apresentado mais sobre integração de Sistemas de Gestão da Qualidade, Gestão Ambiental e Gestão da Saúde e Segurança no Trabalho. Além disto, outros sistemas, como por exemplo de Responsabilidade Social com base na norma SA 8000 e da Gestão de Risco, podem ser inseridos.

Buscou-se mostrar com o exemplo de aplicação prática a complexidade que é o assunto integração de sistemas de gestão e que uma abordagem sistêmica e a utilização de matemática podem trazer nova luz ao assunto. A abordagem sistêmica permite visualizar um SIG como um sistema que pode falhar e por isso mesmo deve ser monitorado e, como outro qualquer sistema, necessita de manutenção, ou seja, o SIG deve ser abordado como um sistema aberto, dinâmico e flexível.

Há vantagens e desvantagens na integração de sistemas de gestão e a sua integração merece um estudo de projeto para verificar a sua adequação ao momento que a organização está passando, dentro de certo contexto de mercado. A integração pode ser realizada parcialmente, totalmente, entre dois ou mais sistemas. A integração de normas é uma parte do processo do SIG, há ainda a integração de pessoas, a integração e recursos financeiros, por exemplo. Como já comentado, a teoria dos conjuntos presta-se bem para um melhor entendimento da integração de sistemas de gestão. A programação matemática pode ser aplicada como ferramenta para a tomada de decisão de uma integração.

Não foi identificado na literatura nenhum estudo sobre a viabilidade de se realizar uma integração de sistemas, sobre a sua monitoração e manutenção nem sobre o uso da matemática como auxílio nos estudos e análises de integração de sistemas de gestão. Tampouco foram encontrados estudos sobre o uso da programação matemática servindo como suporte na tomada de decisão na integração de sistemas de gestão, onde o objetivo é a otimização de recursos com vistas à minimização de custos, à alocação dos recursos, que sistemas integrar e quando, através da programação matemática. A análise combinatória permite quantificar o número de possíveis áreas de interseção.

A visão sistêmica permite enxergar os sistemas de gestão com maior amplitude e a questão da integração deixa de ser vista apenas como um confronto de requisitos de normas, passando a ser mais dinâmica no sentido de se sair dos modelos de integração, para uma etapa anterior, que é a de análise da viabilidade, projeto, implantação, monitoramento e realimentação e manutenção. Isto pode permitir até, em um dado contexto, mudanças radicais como desmembramento do sistema integrado e ou integração com outros sistemas. A evolução do ambiente à luz da matemática pode dar suporte à decisão nesse processo dinâmico de integração de sistemas de gestão.

\section{Artigo recebido em 12/12/2004 Aprovado para publicação em 10/10/2008}




\section{AGRADECIMENTOS}

Os autores agradecem o apoio recebido da CELPE para concretização deste trabalho e do Conselho Nacional de Desenvolvimento Científico e Tecnológico (CNPq), entidade governamental brasileira promotora do desenvolvimento científico e tecnológico.

\section{REFERÊNCIAS}

AGUIRRE, L. Introdução à identificação de sistemas: técnicas lineares e não-lineares aplicados a sistemas reais. Belo Horizonte: UFMG, 2000.

ABNT, Associação Brasileira de Normas Técnicas. NBR ISO 9001: 2000 - Sistema de gestão da qualidade - Requisitos. Rio de Janeiro: ABNT, 2000.

ABNT, Associação Brasileira de Normas Técnicas. NBR ISO 9004: 2000 - Sistema de gestão da qualidade - Diretrizes para melhorias de desempenho. Rio de Janeiro: ABNT, 2000.

ABNT, Associação Brasileira de Normas Técnicas. NBR ISO 14001: 2004 - Sistema de gestão ambiental - Especificações e diretrizes para uso. Rio de Janeiro: ABNT, 2000.

BERTALANFFY, L. Teoria geral dos sistemas. 2 ed. Petrópolis: Vozes, 1975

BRITISH STANDARDS INSTITUTION. BS 8800: guide to occupational health and safety management systems. London, 1996.

BRITISH STANDARDS INSTITUTION. OHSAS 18001: occupational health and dafety assessment series. London, 2007.

CANSANÇÃO, W. O.; SILVESTRE, M.; DE MEDEIROS, D. The ways to implement an integrated management system. In: Anais do IV SIMPOI/POMS, 2001. p. 189-195.

CANSANÇÃO, W. O.; SILVA, G. C. S.; LOPES, S. L. L. ; DE MEDEIROS, D. D. Proposta de um modelo integrado de gestão dos sistemas ISO 9000 e ISO 14000. In: XXIII ENEGEP, 2003, Ouro Preto.

CHAN, Y. et al. The establishment of an integrated management system - a paradigm for railway engineering management. The TQM Magazine, v. 10, n. 6, p. 420, 1998.

CORNACHIONE JÚNIOR, E. Sistemas Integrados de Gestão: uma abordagem da tecnologia da informática aplicada a gestão econômica (Gecon) arquitetura, método, implantação. São Paulo: Atlas, 2001.

CROWE, T. Integration is not synonymous with flexibility. International Journal of Operations and Production Management, v. 12, n. 1, p. 26-33, 1992.

GIL, A. Métodos e técnicas de pesquisa social. 6. ed. São Paulo: Atlas, 2008.

HARRINGTON, H.; CARR, J; REID, R. What's this "systems" stuff, anyhow? The TQM Magazine, v. 11, n. 1, p. 54, 1999.
KARAPETROVIC, S. Strategies for the integration of management systems and standards. The TQM Magazine, v. 14, n. 1, p. 61-67, 2002.

KARAPETROVIC, S.; WILLBORN, W. Integration of quality and environmental management systems. The TQM Magazine, v. 10, n. 3, p. 204-213, 1998.

MACIEL, J. Elementos de teoria geral dos sistemas. Petrópolis: Vozes, 1974.

MACKAU, D. SME integrated management system: a proposed experiences model. The TQM Magazine, v. 15, n. 1, p. 43-53, 2003.

POMBO, F.; MAGRINI, A. Panorama de aplicação da norma ISO 14001 no Brasil. Gestão \& Produção, São Carlos, v. 15, n. 1, 2008.

RAMPAZZO, L. Metodologia científica. São Paulo: Loyola, 2002.

SISSEL, K. One size fits all: unifying ISO management. Chemical Week, v. 158. n. 13, p. 27-36, 1996.

WILKINSON, G.; DALE, B. Integrated management systems: an examination of the concept and theory. The TQM Magazine, v. 11, n. 2, p. 95-104, 1999.

\section{SOBRE OS AUTORES}

Carlos Alberto de Oliveira Campos

Departamento de Engenharia de Produção

Universidade Federal de Pernambuco

End.: Rua Acadêmico Hélio Ramos, s/n - 50740-530 - Recife - PE

E-mail:ccampos@celpe.com.br

\section{Denise Dumke de Medeiros}

Departamento de Engenharia de Produção

Universidade Federal de Pernambuco

End.: Rua Acadêmico Hélio Ramos, s/n - 50740-530 - Recife - PE

E-mail: ddm@ufpe.br 